\title{
CARACTERÍSTICAS FISIOGRÁFICAS DA BACIA HIDROGRÁFICA DO RIO PIRACURUCA (CE-PI)
}

\author{
Francílio de Amorim dos Santos ${ }^{(a)}$, Lúcia Maria Silveira Mendes ${ }^{(b)}$, Maria Lúcia Brito da Cruz ${ }^{(\mathrm{c})}$ \\ (a)Instituto Federal do Piauí / Campus Piripiri, E-mail: francilio.amorim@ifpi.edu.br \\ (b)Universidade Estadual do Ceará / Campus do Itaperi, E-mail: lucia.mendes@uece.br \\ (c)Universidade Estadual do Ceará / Campus do Itaperi, E-mail: $\underline{\text { mlbcruz@ gmail.com }}$
}

\section{Eixo: GEOTECNOLOGIAS E MODELAGEM ESPACIAL EM GEOGRAFIA FÍSICA}

\begin{abstract}
Resumo
Os objetivos deste estudo foram identificar e caracterizar os elementos fisiográficos que compõem a bacia hidrográfica do rio Piracuruca (BHRP), para subsidiar pesquisas futuras voltadas ao planejamento e gestão dos recursos hídricos na referida bacia. A metodologia adotada consistiu no uso de modelo digital de elevação (MDE) para delimitação da bacia e análise de suas variáveis morfométricas. Os resultados evidenciaram que o padrão de drenagem da bacia é dendrítico, com sistema de drenagem de $6^{\mathrm{a}}$ ordem. A BHRP sofre influência da Zona de Convergência Intertropical (ZCIT), com chuvas concentradas entre janeiro a maio. Observou-se predomínio de Neossolos na BHRP, que apresentam maior suscetibilidade em relação a processos erosivos, caso sejam utilizadas técnicas de manejo inadequadas. Constatou-se que a área possui relativa predisposição a inundações, devido fator forma $(F f)$ de 0,46 , índice de circularidade $(I c)$ de 0,34 , coeficiente de compacidade $(K c)$ de 1,7 e índice de rugosidade (Ir) que indica baixa predisposição a enchentes abruptas.
\end{abstract}

Palavras chave: Bacia de drenagem; elementos geoambientais; variáveis morfométricas.

\section{Introdução}

A bacia hidrográfica tem sido utilizada como elemento chave para estudos ambientais, pois se apresenta como um sistema aberto, permitindo trocas de matéria e energia entre seus elementos constituintes e, por conseguinte, o conhecimento de suas características fisiográficas fornece subsídios para a aplicação de adequadas técnicas de manejo e/ou conservação para o uso das terras nestas áreas. Fistarol et al. (2015, p.44) aponta que "[...] a bacia hidrográfica é uma unidade natural que recebe a influência da região que drena, é um receptor de todas as interferências naturais e antrópicas que ocorrem na sua área”.

Nesse contexto, têm sido utilizadas diversas técnicas para caracterização fisiográfica e, nesse sentido, Carelli et al. (2011) apontam que as técnicas de geoprocessamento são as principais ferramentas utilizadas para análise dos elementos físicos, cujo objetivo busca avaliar de forma integrada os sistemas naturais e possibilitam a otimização dos estudos dos recursos naturais. Nesse sentido, cita-se o uso de técnicas de delimitação automática de bacias hidrográficas em ambiente SIG, utilizando dados Shuttle Radar Topography Mission (SRTM), como proposto por Alves Sobrinho (2010). 


\section{OS DESAFIOS DA GEOGRAFIA FÍSICA NA FRONTEIRA DO CONHECIMENTO \\ Instituto de Geociências - Unicamp \\ Campinas - SP \\ 28 de Junho à 02 de Julho de 2017}

Duarte et al. (2007) buscaram extrair as características físicas e topográficas e correlaciona-las aos fatores de precipitação e temperatura da bacia hidrográfica do rio Tapacurá (PE), com a utilização de Sistemas de Informação Geográfica. Os autores constataram que os controles estruturais influenciaram a morfologia da bacia, que se apresenta alongada, irregular e com mudanças bruscas de direção dos rios. Nesse sentido, o cálculo do coeficiente de compacidade, do fator de forma e índice de circularidade apresentaram 1,8024, 0,1818 e 0,3034, respectivamente. Ressalta-se que quanto mais próximo a 1,0 estiverem os valores de $F f$ e o Ic mais circular é a bacia e maior o potencial de transformação da chuva em escoamento, até a sua chegada ao setor de controle. O sistema de drenagem da área estudada é de $6^{a}$ ordem e sua densidade de drenagem foi estimada em $1,4892 \mathrm{~km} / \mathrm{km}^{2}$, fato que demonstra que a área exibe um sistema de drenagem com ramificação significativa.

Carelli et al. (2011), em estudo sobre a caracterização fisiográfica da bacia Olhos d'água em Feira de Santana/BA, identificou que o referido recurso hídrico apresenta média capacidade de drenagem, possuindo uma densidade de drenagem de $1,95 \mathrm{~km} / \mathrm{km}^{2}$, coeficiente de compacidade de 1,47 e fator de forma com valor de 0,28 , que resulta em pouca susceptibilidade a enchentes em condições normais de precipitação, devido apresentar forma irregular, índice de circularidade de 0,45 , ou seja, forma alongada. A área demonstra suscetibilidade potencial à inundação quando da ocorrência de um evento de maior concentração de chuvas, devido exibir alta densidade hidrográfica, degradação da vegetação, impermeabilização da área e concentração de residências às margens do curso hídrico.

Fistarol et al. (2015) propuseram-se a analisar as características físicas da bacia do Rio de Ondas com a utilização de técnicas de geoprocessamento e sensoriamento remoto. Seus resultados apontaram que a referida área possui coeficiente de compacidade estimado em 1,98 e o fator forma em 0,25, o que implica que não é sujeita a enchentes, devido apresentar forma irregular e alongada. A bacia possui drenagem pobre, pois sua densidade de drenagem foi estimada em $0,23 \mathrm{~km} / \mathrm{km}^{2}$ e em relação a sua altitude possui cotas que variam de $445 \mathrm{~m}$ a leste até $924 \mathrm{~m}$ a oeste. Cita-se, ainda, que a área apresenta baixa declividade, com a maior parte da área situada no intervalo entre as declividades de 0 a $10 \%$.

Diante do exposto, esta pesquisa objetivou identificar e caracterizar os elementos fisiográficos que compõem a bacia hidrográfica do rio Piracuruca (BHRP), localizada entre os estados do Ceará e Piauí, como forma de subsidiar pesquisas futuras voltadas ao planejamento e gestão dos recursos hídricos na bacia homônima, para sua conservação e minimização das susceptibilidades a inundações. 


\section{Metodologia}

Inicialmente, fez-se necessário adquirir modelo digital de elevação (MDE), folhas SA-24-Y-C e SB-24-VA, da missão Shuttle Radar Topography Mission (SRTM), com resolução espacial de 30 metros, junto ao site <http://earthexplorer.usgs.gov/>, do United States Geological Service (USGS). Em seguida, procedeuse ao uso da técnica de delimitação automática de bacias hidrográficas, que converte em vetores as feições de drenagem e os divisores de água, como atestam Alves Sobrinho (2010) e Silva e Moura (2013). A delimitação automática foi realizada via Sistema de Informação Geográfica (SIG) ArcGIS, versão 10 (ESRI, 2010), cuja licença foi adquirida pelo Laboratório de Geomática da Universidade Federal do Piauí (UFPI), cujos procedimentos e ferramentas utilizadas estão dispostas abaixo (Figura 1).

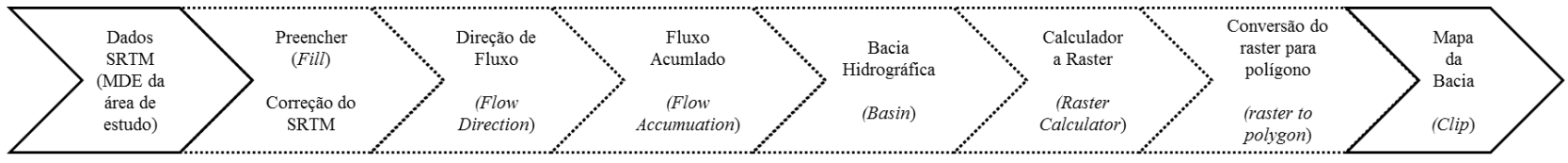

Figura 1 - Etapas realizadas para delimitação da bacia hidrográfica do rio Piracuruca (BHRP) a partir do MDE SRTM (USGS, 2015). Fonte: Adaptado de Alves Sobrinho (2010).

Após a delimitação da BHRP, procederam-se à análise das variáveis morfométricas considerando cinco parâmetros geométricos, quatro da rede de drenagem e cinco referentes ao relevo (Quadro 1).

Quadro 1 - Parâmetros morfométricos utilizados na análise da bacia hidrográfica do rio Piracuruca.

\begin{tabular}{|c|c|c|c|c|}
\hline Variável & Parâmetro & Equação & Definição & Unidade \\
\hline \multirow{5}{*}{ } & Área $(A)$ & $A$ & $A=$ área da bacia em $\mathrm{km}^{2}$. & $\mathrm{km}^{2}$ \\
\hline & Perímetro $(P)$ & $P$ & $P=$ perímetro da bacia em $\mathrm{km}^{2}$. & $\mathrm{km}^{2}$ \\
\hline & Fator forma da bacia $(F f)$ & $F f=\frac{A}{L^{2}}$ & $\begin{array}{c}A=\text { área da bacia em } \mathrm{km}^{2} ; \\
L=\text { comprimento do eixo }(\mathrm{km}) .\end{array}$ & - \\
\hline & $\begin{array}{l}\text { Índice de circularidade } \\
\text { (IC) }\end{array}$ & $I c=12,57 \frac{A}{p^{2}}$ & $\begin{array}{c}A=\text { área da bacia em } \mathrm{km}^{2} \\
p=\text { perímetro da bacia em } \mathrm{km}^{2} .\end{array}$ & - \\
\hline & $\begin{array}{l}\text { Coeficiente de } \\
\text { compacidade }(K c)\end{array}$ & $K c=\frac{0,28 p}{\sqrt{A}}$ & $\begin{array}{c}A=\text { área da bacia em } \mathrm{km}^{2} ; \\
P=\text { perímetro da bacia em } \mathrm{km}^{2} .\end{array}$ & - \\
\hline \multirow{4}{*}{ 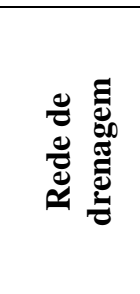 } & $\begin{array}{l}\text { Comprimento total dos } \\
\text { cursos d'água ( } L \text { total) }\end{array}$ & $L$ & $\begin{array}{c}L=\text { comprimento total dos cursos d'água } \\
(L \text { total em } \mathrm{km})\end{array}$ & $\mathrm{km}$ \\
\hline & $\begin{array}{l}\text { Densidade de drenagem } \\
(D d)\end{array}$ & $D d=\frac{L t}{A}$ & $\begin{array}{c}L t=\text { comprimento total dos canais em } \mathrm{km} ; \\
A=\text { área da bacia em } \mathrm{km}^{2} .\end{array}$ & $\mathrm{km} / \mathrm{km}^{2}$ \\
\hline & $\begin{array}{c}\text { Coeficiente de } \\
\text { manutenção }(\mathrm{Cm})\end{array}$ & $C m=\frac{1}{D d} \times 1000$ & $D d=$ densidade de drenagem em $\mathrm{km} / \mathrm{km}^{2}$ & $\mathrm{~m}^{2} / \mathrm{m}^{-1}$ \\
\hline & Ordem dos cursos d'água & - & - & - \\
\hline \multirow{5}{*}{ 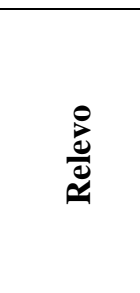 } & Altitude mínima & $H_{\min }$ & $H_{\min }=$ altitude mínima & $\mathrm{m}$ \\
\hline & Altitude máxima & $H_{\max }$ & $H_{\max }=$ altitude máxima & $\mathrm{m}$ \\
\hline & Altitude média & $\frac{H_{\min }+H_{\max }}{2}$ & $\begin{array}{l}H_{\min }=\text { altitude mínima; } \\
H_{\max }=\text { altitude máxima }\end{array}$ & $\mathrm{m}$ \\
\hline & Amplitude altimétrica & $H_{t}$ & $H_{t}=$ amplitude altimétrica em $\mathrm{m}$ & $\mathrm{m}$ \\
\hline & Índice de rugosidade (Ir) & $I r=H x D d$ & $\begin{array}{c}H=\text { amplitude altimétrica em } \mathrm{m} ; \\
\text { Dd = densidade de drenagem em } \mathrm{km} / \mathrm{km}^{2} .\end{array}$ & - \\
\hline
\end{tabular}

Fonte: Soares e Souza (2012). Adaptado pelos autores (2017) 


\section{Localização da área em estudo}

A BHRP drena uma área total de 7.625,9 km². A BHRP é uma bacia interestadual situando-se no norte dos estados do Ceará e Piauí (Figura 2), constituindo-se uma sub-bacia da bacia hidrográfica do rio Longá (BHRL). O rio Piracuruca nasce na Serra da Ibiapaba, a altura do município de São Benedito, no estado do Ceará, e deságua no rio Longá a altura do município de São José do Divino, já no estado do Piauí.

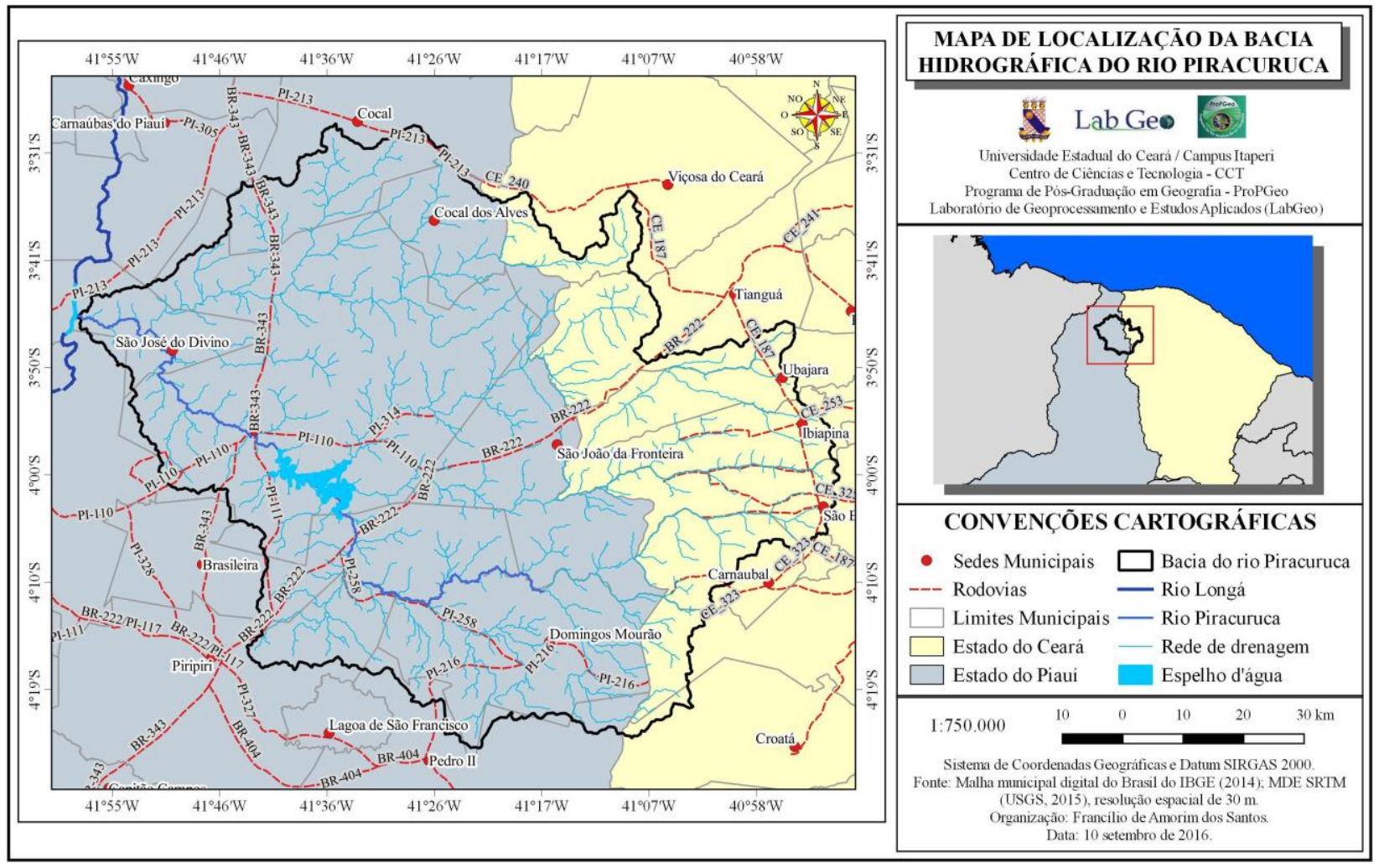

Figura 2 - Localização da bacia hidrográfica do rio Piracuruca (BHRP), obtido através da extração de bacias via dados de altimetria do MDE SRTM (USGS, 2015).

Predomina na BHRP o tipo climático subúmido úmido, embora ocorram também os tipos subúmido seco e úmido. A referida bacia apresenta totais de precipitação pluviométrica anual média que variam de $710 \mathrm{~mm}$ a $1.710 \mathrm{~mm}$ e temperatura anual média no intervalo entre $20^{\circ} \mathrm{C}$ a $27^{\circ} \mathrm{C}$. Essas características são provenientes da localização da BHRP, que sofre influência da Serra da Ibiapaba, ou seja, devido efeito orográfico (SANTOS e CRUZ, 2016). 


\section{Resultados e discussão}

\subsection{Análises Fisiográficas}

A bacia hidrográfica do Rio Piracuruca (BHRP) estende-se por seis diferentes formações geológicas (Figura 3). Pode-se observar que o Grupo Serra Grande ocupa 37\% da área da BHRP e é formação por conglomerados, arenitos e intercalações de siltitos e folhelhos (CPRM, 2006). A formação Pimenteiras é a segunda mais extensa da bacia estudada, abrangendo $23,6 \%$ do referido curso hídrico, sendo formada por arenitos, siltitos e folhelhos (CPRM, 2006). A terceira formação mais extensa é a formação Cabeças, que se distribui por $21,8 \%$ da área estudada, sendo formada por arenitos e siltitos (CPRM, 2006). As outras três formações distribuem-se por $12,6 \%, 4,9 \%$ e $0,1 \%$ da bacia, respectivamente, Depósitos ColúvioEluviais, Formação Sardinha e Formação Longá.

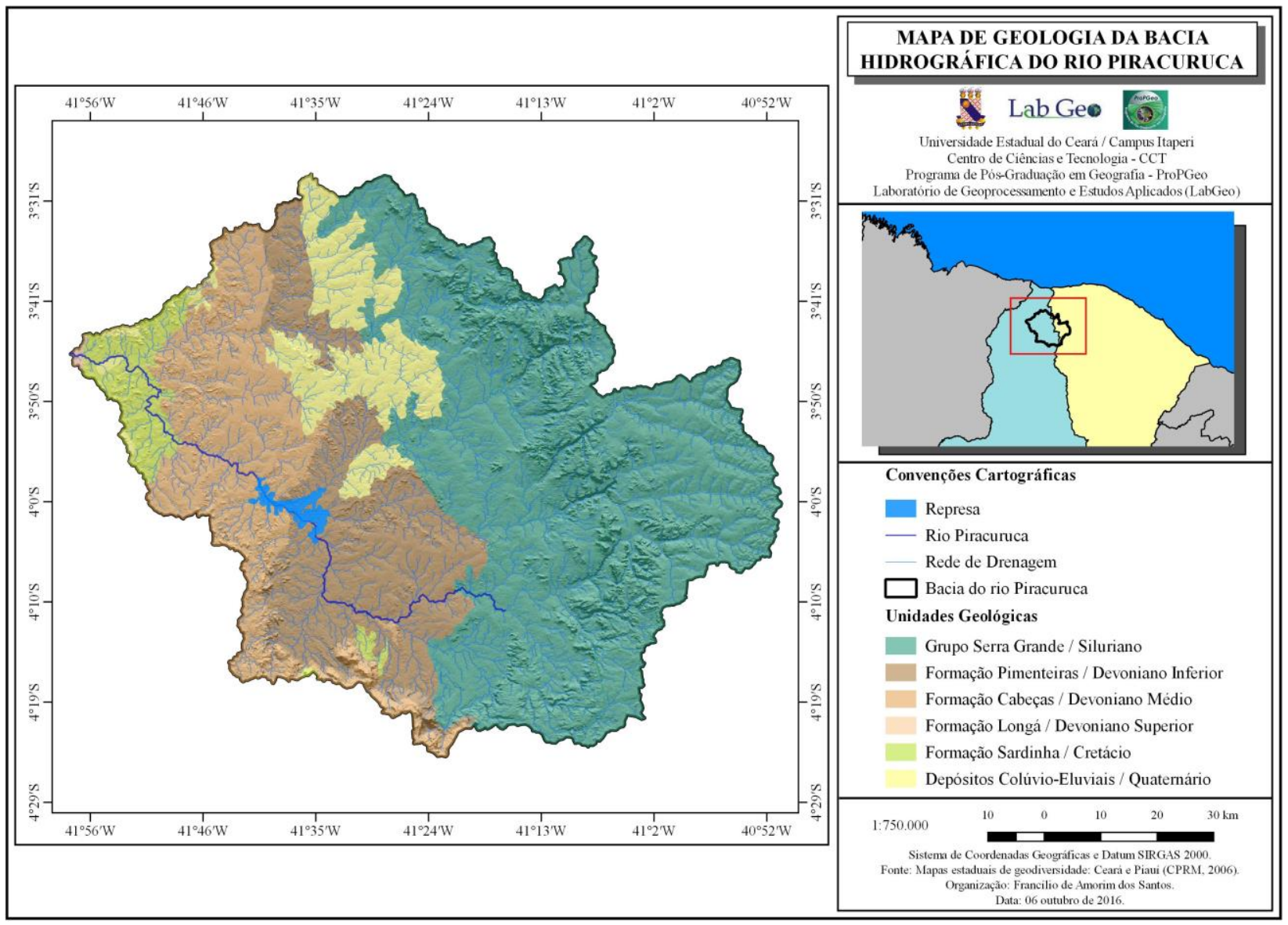

Figura 3 - Esboço geológico da bacia hidrográfica do rio Piracuruca (BHRP), obtido via dados vetoriais da geodiversidade estadual do Ceará e do Piauí (CPRM, 2006).

O rio, que tem suas nascentes no município cearense de São Benedito, surge a mais de $893 \mathrm{~m}$ de altitude na Serra da Ibiapaba. O mesmo após percorrer cerca de 200 km e deságua no município de São José do 


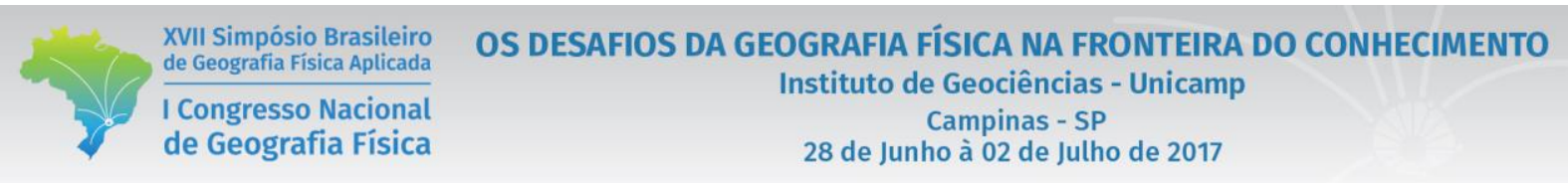

Divino, já no estado do Piauí, com cotas abaixo de $46 \mathrm{~m}$. Nesse sentido, pode-se afirmar que o rio principal da BHRP apresenta um desnível médio de 4,2 $\mathrm{m} / \mathrm{km}$. Diga-se, ainda, que a BHRP apresenta rios com padrão de drenagem dendrítica, segundo classificação de Christofoletti (1980), e é classificada como um sistema de drenagem de $6^{\mathrm{a}}$ ordem (Figura 4), de acordo com a proposta de Strahler (1952), tendo o Piracuruca como seu rio principal.

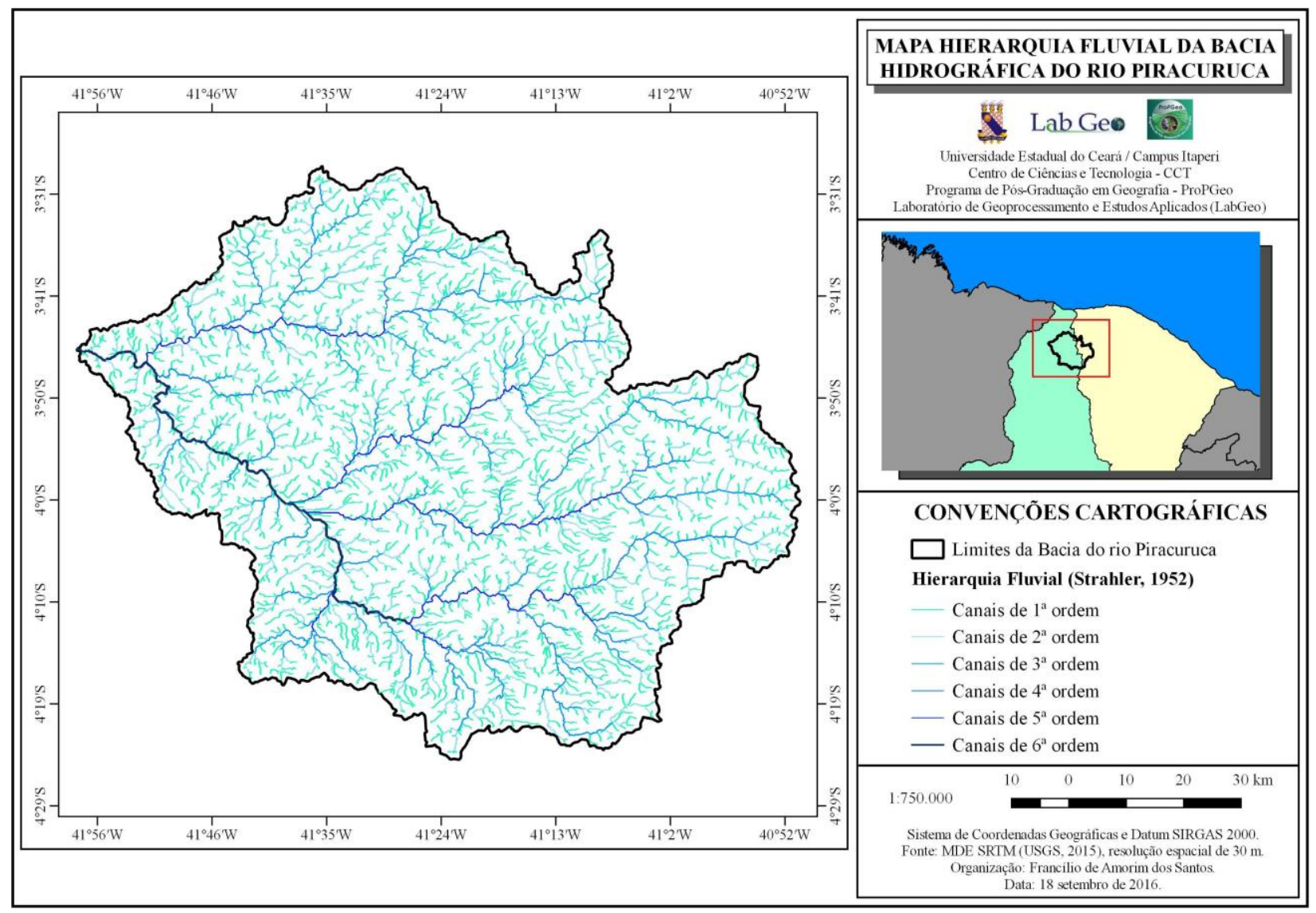

Figura 4 - Hierarquia fluvial da bacia hidrográfica do rio Piracuruca, conforme proposta de Strahler (1952).

A BHRP sofre influência da Zona de Convergência Intertropical (ZCIT), que produz chuvas concentradas principalmente de janeiro a maio. Com a espacialização dos dados de precipitação pluviométrica dos postos da Agência Nacional de Águas (ANA) pode-se visualizar que as chuvas na BHRP variam de 710 a $1.710 \mathrm{~mm}$ anuais (Figura 5). Ao passo que o maior nível de precipitação localiza-se na parte centro-leste (1.110 a $1.310 \mathrm{~mm}$ anuais), esta exibe influência do fator orográfico oriundo a Serra da Ibiapaba. A parte Sudeste a Sul destaca-se por apresentar totais pluviométricos típicos do semiárido ( 710 a 810 mm anuais). 

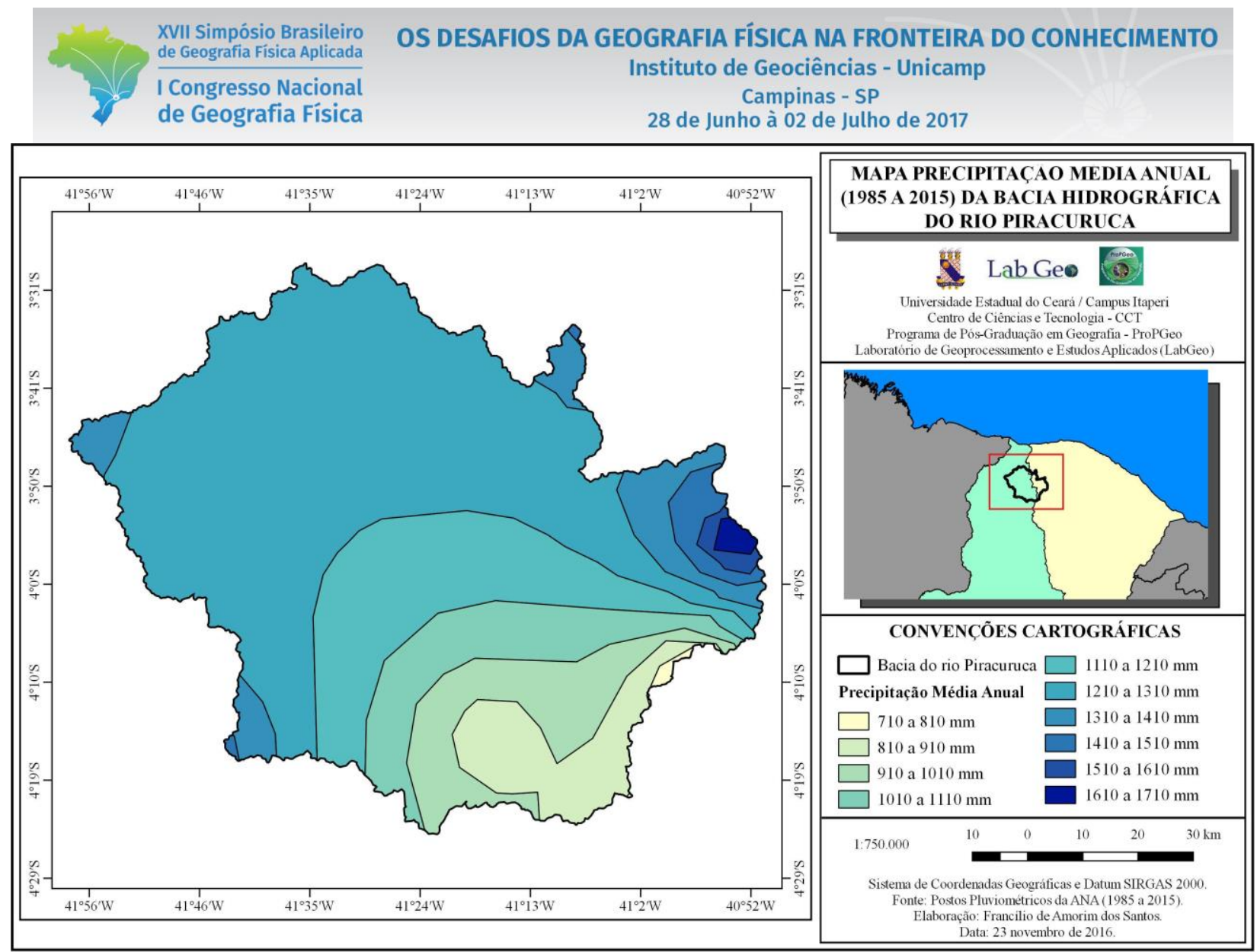

Figura 5 - Precipitação pluviométrica anual média $(\mathrm{mm})$ da bacia hidrográfica do rio Piracuruca (BHRP), obtido por meio dos dados das planilhas dos postos pluviométricos da ANA (2016).

Na BHRP predominam os Neossolos Quartzarênicos Órticos, visto que se distribuem por 36,2\% da área (Figura 6). A segunda maior abrangência diz respeito aos Neossolos Litólicos Distróficos, que se distribuem por $21,7 \%$ da referida bacia de drenagem. A terceira que se destaca está relacionada aos Latossolos Amarelos Distróficos, abrangendo 9,4\% da bacia. Nesse sentido, é possível observar que em sua maior parte a BHRP apresenta solos jovens e como tal merecem atenção e técnicas de manejo adequadas, quando do seu uso para o desenvolvimento de atividades humanas. 

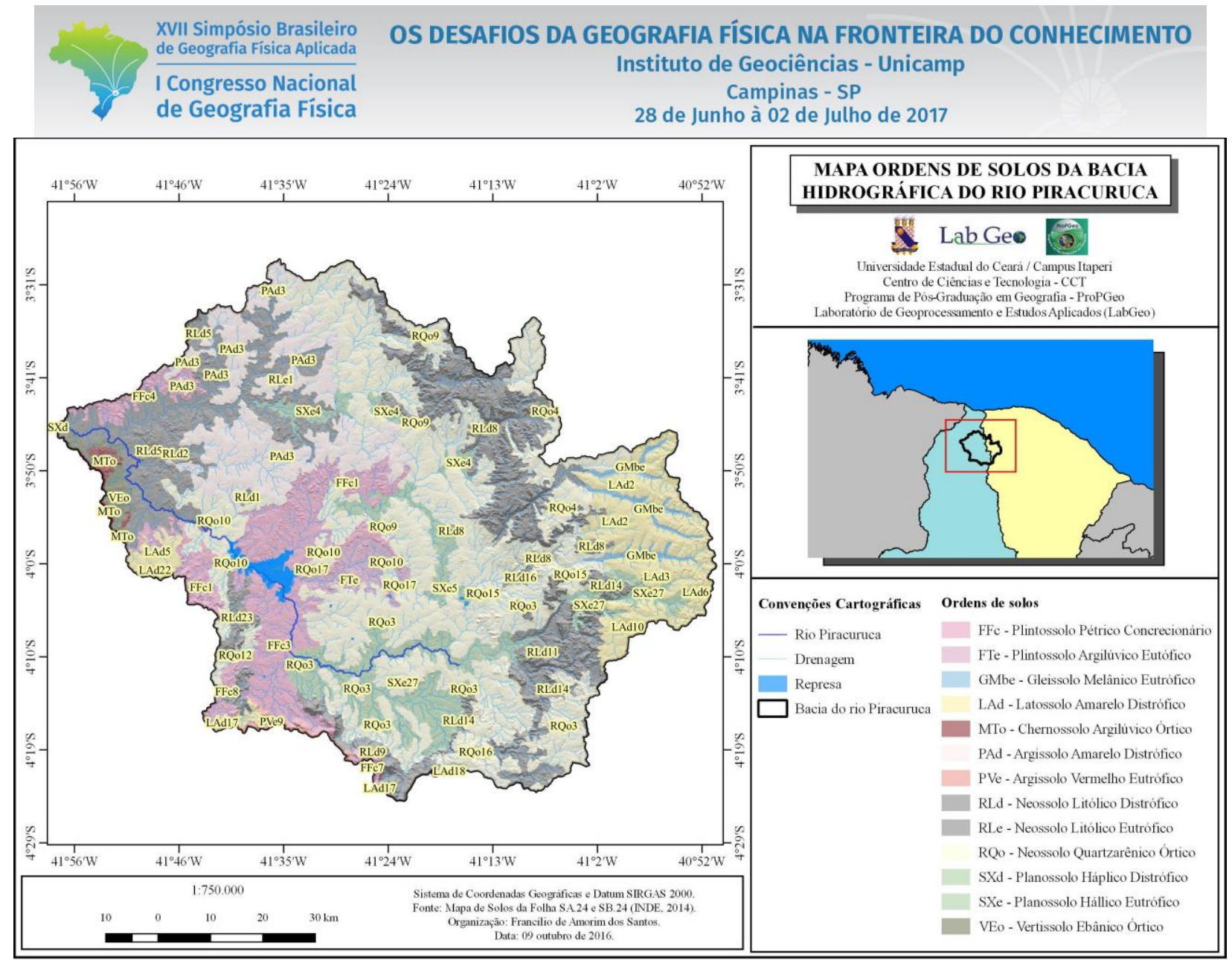

Figura 6 - Esboço das ordens de solos da bacia hidrográfica do rio Piracuruca (BHRP), obtido mediante dados vetoriais da INDE (2014).

\subsection{Análises morfométricas}

O estudo possibilitou identificar que a área estudada exibe fator forma $(F f)$ de 0,46 , considerado um valor médio e, desse modo, pode-se afirmar que a BHRP apresenta uma forma intermediária (Quadro 2). Ressalta-se que uma forma mais irregular dificulta o acúmulo rápido da água das chuvas e, por conseguinte, menor predisposição a eventos extremos de inundações. Logo, o índice aponta relativa probabilidade a eventos de inundações a exemplo do $F f$ de 0,61 encontrado para a Bacia do rio Seridó (RN/PB), no estudo de Pereira Neto (2015). O mesmo autor afirma que “[...] o aporte hídrico no canal fluvial tende a se concentrar em um menor espaço de tempo (com o pico de vazão ou deflúvio)" (PEREIRA NETO, 2015, p.256).

O índice de circularidade (Ic) foi de 0,34, indicando que a BHRP tende a apresentar uma forma mais alongada que circular, não favorecendo processos de inundação, pois esse tipo de forma produz um escoamento mais bem distribuído no tempo e, consequentemente, baixo potencial a enchentes. Um valor semelhante foi identificado por Ferreira et al. (2010), em estudo na bacia hidrográfica do Açude Cachoeira 
II, em Serra Talhada (PE), com Ic de 0,37, indicando menor risco a grandes cheias sob condições normais de pluviosidade anual, ao passo que a topografia apresenta-se favorável ao escoamento superficial.

Quadro 2 - Características morfométricas analisadas da bacia hidrográfica do rio de Piracuruca (BHRP).

\begin{tabular}{|c|c|c|}
\hline Variáveis & Parâmetro & Unidade \\
\hline \multirow{4}{*}{ Geométrica } & Área $(A)$ & $7.625,9 \mathrm{~km}^{2}$ \\
\cline { 2 - 3 } & Perímetro $(P)$ & $526,4 \mathrm{~km}^{2}$ \\
\cline { 2 - 3 } & Fator forma da bacia $(F f)$ & 0,46 \\
\cline { 2 - 3 } & Índice de circularidade $(I c)$ & 0,34 \\
\cline { 2 - 3 } Rede de & Coeficiente de compacidade $(K c)$ & 1,7 \\
\cline { 2 - 3 } drenagem & Comprimento total dos cursos d'água $(L$ total $)$ & $6.046,5 \mathrm{~km}$ \\
\cline { 2 - 3 } & Densidade de drenagem $(D d)$ & $0,8 \mathrm{~km} / \mathrm{km}^{2}$ \\
\cline { 2 - 3 } Relevo & Coeficiente de manutenção $(C m)$ & $1.250 \mathrm{~m}^{2} / \mathrm{m}^{-1}$ \\
\hline \multirow{4}{*}{} & Ordem dos cursos d'água & $6^{\mathrm{a}}$ \\
\cline { 2 - 3 } & Altitude mínima $\left(H_{\min }\right)$ & $86 \mathrm{~m}$ \\
\cline { 2 - 3 } & Altitude máxima $\left(H_{\max }\right)$ & $469,5 \mathrm{~m}$ \\
\cline { 2 - 3 } & Altitude media & $847 \mathrm{~m}$ \\
\cline { 2 - 3 } & Amplitude altimétrica máxima & 677,6 \\
\cline { 2 - 3 } & Índice de rugosidade $(I r)$ & 1 \\
\hline
\end{tabular}

A forma alongada da bacia é corroborada pelo coeficiente de compacidade $(K c)$ de 1,7, não favorecendo a ocorrência de picos de enchentes e, por outro lado, possibilitando maior escoamento. Ferreira et al. (2010) encontrou o $K c$ de 1,63 para a bacia do rio Seridó e propõe que a mesma apresenta susceptibilidade ao escoamento devido ser mais alongada.

Em relação aos parâmetros da rede de drenagem, o comprimento total dos cursos d'água ( $L$ total) da BHRP é de $6.045,5 \mathrm{~km}$. Sua densidade de drenagem $(D d)$ foi estimada em $0,8 \mathrm{~km} / \mathrm{km}^{2}$, indicando uma rede de drenagem regular. $\mathrm{O}$ seu coeficiente de manutenção $(\mathrm{Cm})$ demonstrou a necessidade de $1.250 \mathrm{~m}^{2}$ para manter perene cada metro de seus canais. Cabe, ainda, mencionar que a soma do comprimento de todos os canais da bacia é $6.046,5 \mathrm{~km}$.

Em relação ao relevo da bacia em estudo, o mesmo apresenta cota altimétrica mínima de $46 \mathrm{~m}$ e máxima de $893 \mathrm{~m}$, por conseguinte média altimétrica de 469,5 m e amplitude de $847 \mathrm{~m}$. No que tange ao índice de rugosidade (Ir) a área apresenta um relevo dissecado em colinas e vertentes curtas, o que define baixa predisposição a enchentes abruptas.

\section{Conclusões}

O conhecimento das características fisiográficas constitui-se importante elemento para compreensão da dinâmica geoambiental, bem como identificação das potencialidades e limitações de uma bacia 
hidrográfica, que no presente estudo teve como objeto a bacia hidrográfica do rio Piracuruca (BHRP), visando subsidiar as práticas humanas e minimizar os riscos a desastres naturais.

A área estudada é uma bacia interestadual, devido o rio Piracuruca ter suas nascentes no município cearense de São Benedito, há mais de $890 \mathrm{~m}$ de altitude na Serra da Ibiapaba, e desaguar no município de São José do Divino, estado do Piauí, com cotas de 46 m. Pode-se observar, ainda, que a BHRP assenta-se sobre formações geológicas com diferentes litologias, cuja composição abrange principalmente conglomerados, arenitos, siltitos e folhelhos, que com técnicas apropriadas podem ser explorados.

A BHRP apresenta influência da Zona de Convergência Intertropical (ZCIT), que promove concentração de chuvas entre janeiro a maio. A área exibe, também, concentração de chuvas no lado cearense, devido o fator orográfico proveniente da Serra da Ibiapaba, enquanto a parte Sudeste e Sul possui totais pluviométricos típicos de clima subúmido seco a semiárido. Predominam na área da bacia os Neossolos (Quartzarênicos Órticos e Litólicos Distróficos), que devido serem pouco desenvolvidos exibem maior possibilidade de degradação quando do uso de técnicas de manejo e/ou conservação inadequadas.

Quando analisados os parâmetros morfométricos da BHRP, pode-se constatar que a mesma possui relativa probabilidade a enchentes, visto que apresenta fator forma $(F f)$ de 0,46, índice de circularidade (Ic) de 0,34 e coeficiente de compacidade $(K c)$ de 1,7, além de índice de rugosidade (Ir) que aponta baixa predisposição a enchentes abruptas. Entretanto, é importante frisar que esses índices foram mensurados para a bacia de modo geral, devendo-se aplica-los para conhecimento de forma setorizada e, como tal, identificar a real predisposição do alto, médio e baixo curso da BHRP a eventos de enchentes.

\section{Referências}

ALVES SOBRINHO, T. Delimitação automática de bacias hidrográficas utilizando dados SRTM. Engenharia Agrícola, Jaboticabal, v.30, n.1, p.46-57, jan./fev. 2010.

CARELLI, L.; LOPES, P.P. Caracterização Fisiográfica da Bacia Olhos D’água em Feira de Santana/BA: Geoprocessamento Aplicado à Análise Ambiental. Boletim Goiano de Geografia. Goiânia, v. 31, n. 2, p. 43-54, jul./dez. 2011.

CHRISTOFOLETTI, A. Geomorfologia fluvial. Volume 1 - O canal fluvial. São Paulo: Edgard Blücher, 1981.

Geomorfologia. 2.ed. rev. e ampl. São Paulo: Edgard Blücher, 1980.

CPRM - Serviço Geológico do Brasil. Ministério de Minas e Energia. Mapas estaduais de geodiversidade: Piauí. Rio de Janeiro: CPRM. 2006. Documento cartográfico em arquivo vetorial. Disponível em http://geobank.sa.cprm.gov.br. Acesso em janeiro de 2014.

DUARTE, C.C.; GALVÍNCIO, J.D.; CORRÊA, A.C.B.; ARAÚJO, M.S.B. Análise fisiográfica da Bacia Hidrográfica do rio Tapacurá- PE. Revista de Geografia, Recife: UFPE - DCG/NAPA, v. 24, n 2, mai/ago. 2007.

FERREIRA, C.W.S.; LIMA, C.S.; CAVALCANTI, L.C.S.; SANTOS, A.H.O. Caracterização morfométrica da Bacia Hidrográfica do Açude Cachoeira II, no município de Serra Talhada - PE, Brasil. In: VI Seminário Latino 


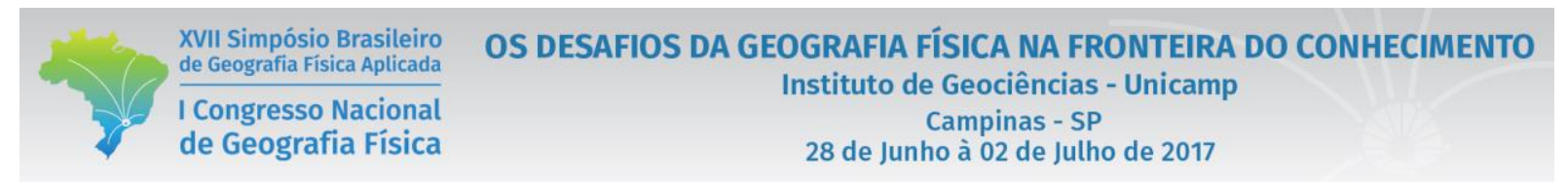

Americano de Geografia Física, II Seminário Ibero Americano de Geografia Física. Anais... Universidade de Coimbra, Maio de 2010.

FISTAROL, P.H.B.; BRANDOLFF, R.S.; SANTOS, J.Y.G. Análise Fisiográfica da Bacia do Rio de Ondas - BA. In: XVII Simpósio Brasileiro de Sensoriamento Remoto - SBSR, INPE, João Pessoa-PB, Brasil. Anais... 25 a 29 de abril de 2015. p.5469-5476.

IBGE - Instituto Brasileiro de Geografia e Estatística. Malha municipal digital do Brasil: situação em 2014. Rio de Janeiro: IBGE, 2014. Disponível em: <ftp://geoftp.ibge.gov.br/malhas_digitais/>. Acesso em 04 de abril de 2016.

Cidades. Disponível em <www.cidades.ibge.gov.br> . Acesso em 10 de setembro de 2016.

PEREIRA NETO, M.C. Análise areal como subsidio aos estudos integrados da Bacia Hidrográfica do rio Seridó (RN/PB). Revista Equador (UFPI), Vol. 5, № 4 (Edição Especial 03), p.250-261. 2015.

SANTOS, F.A.; CRUZ, M.L.B. Balanço hídrico climatológico da Bacia Hidrográfica do rio Piracuruca, Nordeste do Brasil. In: I Congresso Internacional da Diversidade do Semiárido - I CONIDIS. Anais... 10 a 12 de novembro, Campina Grande (PB), 2016.

SILVA, J.R.; MOURA, A.C.M. Delimitação automática de sub-bacias hidrográficas no município de Ouro PretoMG. In: XVI Simpósio Brasileiro de Sensoriamento Remoto - SBSR, INPE, Foz do Iguaçu, PR, Brasil. Anais... 13 a 18 de abril de 2013. p. 4496-4502.

SOARES, M.R.G.J.; SOUZA, J.L.M. Análise morfométrica da Bacia Hidrográfica do Rio Pequeno em São José dos Pinhais (PR). Geografia (Londrina), Londrina, v. 21, n. 1, p.019-036, jan./abr. 2012.

STRAHLER, A.N. Hypsometric analysis of erosional topography. Geological Society of America Bulletin, n. 63, p.111-1141, 1952 .

USGS - United States Geological Service (Serviço Geológico dos Estados Unidos). Earth Explorer - Digital Elevation - SRTM 1 Arc-Second Global. 2015. Disponível em <http://earthexplorer.usgs.gov/>. Acesso em 23 de novembro de 2015 .

\section{Agradecimentos}

Agradecemos ao Laboratório de Geomática, da Universidade Federal do Piauí (UFPI) / Campus Universitário Ministro Petrônio Portela, por ceder espaço e permitir o uso do software ArcGIS, licenciado para o referido laboratório. 